\title{
Öz-Düzenlemeli Öğrenme Uygulamaları Öğretmen Öz-Yeterlik Ölçeği'nin Türk Kültürüne Uyarlanması
}

\author{
Dr.Sevilay Çırak Kurt \\ Adıyaman Üniversitesi-Türkiye \\ sevilaycirak@hotmail.com
}

\author{
Dr.Esen Turan Özpolat \\ Adıyaman Üniversitesi-Türkiye \\ esen.turan@hotmail.com
}

\begin{abstract}
Özet:
Bu araştırma öğretmenlerin sınıflarında öz-düzenlemeli öğrenme uygulamaları bakımından öz-yeterliklerini belirlemeyi sağlayacak "Öz-düzenlemeli Öğrenme Uygulamaları Öğretmen Öz-yeterlik Ölçeği"ni Türk kültürüne uyarlamak ve ölçeğin psikometrik özelliklerini ortaya koymak amacıla yürütülmüştür. Araştırma kapsamında veriler 561 sınıf ögretmeninden toplanmıştır. Ölçeğin yapı geçerliğini incelemek üzere 300 ögretmenden toplanan veri seti ile açımlayıcı faktör analizi, sonrasında 261 ögrretmenden toplanan ayrı bir veri seti ile ise doğrulayıcı faktör analizi işlemleri yürütülmüştür. Yürütülen geçerlik ve güvenirlik çalışmalarına göre 22 madde ve 3 boyuttan (doğrudan öğretim öz-yeterliği; seçenekler sunma özyeterliği; etkinlik sunumu ve değerlendirme süreci öz-yeterliği) oluşan bir yapı elde edilmiştir. Sonuçta, Öz-düzenlemeli Öğrenme Uygulamaları Öğretmen Öz-yeterlik Ölçeği Türkçe formunun öğretmenlerin öz-düzenlemeli ögrrenme uygulamaları bakımından öz-yeterliklerini belirlemek amacıla kullanılabilecek geçerlik ve güvenirliğine ilişkin kanıtlar üretilmiş bir ölçme aracı olduğu söylenebilir.
\end{abstract}

Anahtar Kelimeler: Öz-düzenlemeli öğrenme, Öğretmen öz-yeterliği, Ölçek uyarlama, Geçerlik ve güvenirlik.

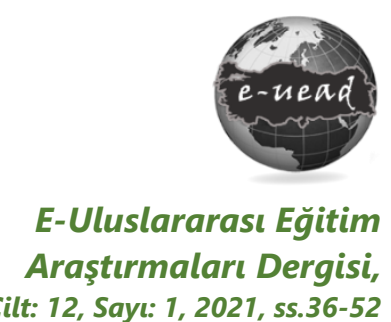

DOI: 10.19160/ijer.758926

Gönderim : 27.06.2020 Kabul : 04.03.2021

\section{Önerilen Atıf}

Çırak Kurt, S. \&. Turan Özpolat, E. (2021). Öz-düzenlemeli öğrenme uygulamalari öğretmen öz-yeterlik ölçeği'nin Türk kültürüne uyarlanması, E-Uluslararası Eğitim Araştırmaları Dergisi, Cilt: 12, Sayı: 1, 2021, ss. 36-52, DOI: 10.19160/ijer.758926 


\section{Giriş}

Hayat boyu öğrenme olgusu özellikle son yıllarda oldukça artan sayıda vurgulanmaktadır (Celuch ve Valdares, 2020; Chen, Ma ve Liu, 2018; Doğan ve Çalışkan Toyoğlu, 2019; Formosa, 2019; Graves, 2018; Gündoğdu, Yüksel, Akyol ve Vural, 2016; Samancı ve Ocakçı, 2017; Şentürk ve Duran, 2020). Öğrencilerin hayat boyu kendi öğrenmelerinin sorumluluğunu alması ve öğrenme süreçlerini yönlendirebilmesi ise eğitimin temel amaçlarından biridir. Bunu yaparken de öğrencilerin kişisel yeteneklerinin farkında oldukları ve onları nasıl olumlu kullanacaklarını bildikleri kabul edilir (İnan ve Yüksel, 2010). Bu noktada öz-düzenlemeli öğrenme olgusu ortaya çıkar. Bolhuis (2003) öz-düzenlemeli öğrenmeyi eğitimin önemli bir hedefi olarak göstermektedir. Winne (2005) ve Zimmerman (2002) da etkili bir hayat boyu öğrenme için yine öz-düzenlemeli öğrenmenin önemini vurgulamaktadır. Dignath ve Büttner (2008), öğretmenlerin öğrencilerde hayat boyu öğrenmeye yönelik beceri geliştirme çabalarının, onların sınıflarında özdüzenlemeli öğrenmeyi teşvik etme becerileri ile açıklanabildiğini belirterek öz-düzenleme ve hayat boyu öğrenme becerilerini ilişkilendirmekte ve bu süreçte öğretmene aktif bir görev tanımlamaktadır.

Dinsmore, Alexander ve Loughlin'e (2008) göre öz-düzenleme ve öz-düzenlemeli öğrenme tanımları birbiriyle ilişkili olarak 1980 'lerde ortaya çıkmıştır. Onlara göre öz-düzenleme ile öz-düzenlemeli öğrenme terimleri birbirinden farklı ancak birbiriyle ilişkili olup özdüzenlemeli öğrenme akademik öğrenme kapsamında yer almaktadır. Öz-düzenleme, zihinsel bir yetenek ya da akademik bir performans becerisi değil, öğrencilerin zihinsel yeteneklerini akademik becerilerine dönüştürmeleri yoluyla kendilerini yönetme sürecidir (Zimmerman, 2002). Öz düzenleme "kişinin öğrenme sürecini başka insanlara veya çevresine bağımlı olmadan kontrol edebilme yeteneği" anlamına da gelmektedir (Israel, 2007). Dolayısıyla öz-düzenlemeli öğrenme, öğrencilerin kendi öğrenmelerini kendi becerileri doğrultusunda gerçekleştirip şekillendirebildikleri aktif bir süreç olarak tanımlanabilir. Öz-düzenlemeli öğrenmenin bir diğer tanımı ise, "bireyin öğrenmede bağımsız olduğu ve biliş, motivasyon ve öğrenme sürecini düzenlediği özgün bir süreç" şeklindedir (Ozan, Çelik ve Kıncal, 2014). De Smul, Heirweg, Van Keer, Devos ve Vandevelde (2018) de öz-düzenlemeli öğrenmenin üstbiliş, motivasyon ve biliş olarak üç ana bileşenden oluştuğunu belirtmektedir. Michalsky ve Schechter'a (2013) göre yapılan bazı araştırmalar, yüksek başarı gösteren öğrencilerin aynı zamanda yüksek derecede özdüzenlemeye sahip olduğunu ve öz-düzenleyici öğrenme öğretiminin öğrencilerin akademik performanslarını arttırdığını göstermektedir. Literatürde zz-düzenlemeli öğrenmenin akademik başarı (Haşlaman ve Aşkar, 2007; Olakanmi ve Gumbo, 2017; Paris ve Paris, 2001; Zimmerman, 1990; Zimmerman ve Bandura, 1994) ve motivasyon üzerinde (Lavasani, Mirhosseini, Hejazi ve Davoodi, 2011; Mahmoodi, Kalantari ve Ghaslani, 2014; Pintrich, 1999) olumlu etkisinin olduğunu ortaya koyan pek çok çalışma yer almaktadır.

Olakanmi ve Gumbo (2017), öğrencilerin soyut konuları anlamlı ve başarılı bir şekilde öğrenebilmeleri için öz-düzenlemeli öğrenme stratejilerinin önemli olduğunu belirtmektedir. Araştırmacılar çalışmalarında ayrıca, öz-düzenlemeli öğrenme öğretiminin başarı ve üstbiliş üzerinde olumlu etkisinin olduğu sonucuna da ulaşmışlardır. Dolayısıyla bu ifadelerle de öğretim sürecinin etkin bir ögesi olan öğretmenlerin öğretim sürecinde, öğrencilerin öz-düzenlemeli öğrenme stratejilerini uygulamalarına yönelik bilgi, beceri ve yeterliklere sahip olmaları gerektiğine işaret edilmektedir.

Öz-düzenlemeli öğrenme stratejileri terimi, bir öğrenme hedefine daha etkin bir şekilde ulaşmayı amaçlayan somut faaliyetleri tanımlamak için kullanılmaktadır (Dignath ve Büttner, 2008). Zimmerman (1989) öz-düzenleyici öğrenme stratejilerini, öğrencilerin amaçladıkları bilgi ve becerileri elde etmek için kullandıkları işlemler ve yöntemler olarak açıklamıştır. Boekaerts ve Corno'nun (2005) ifadesine göre öz-düzenleyici öğrenme stratejileri hakkında çalışan kuramcılar, öğrenmelerini öz-düzenleyen öğrencilerin aktif ve yapıcı bir anlam üretme sürecine girdiğini ve 
bu amaçla da öğrenme ve motivasyonlarını etkilemek için gereken duygu, düşünce ve eylemlerini uyarladıklarını belirtmektedir.

İlgili literatürde öz-düzenlemeli öğrenme stratejilerine yönelik çeşitli sınıflandırmalar (Boekaerts ve Corno, 2005; Garcia ve Pintrich, 1994; Pintrich, 1999, Weinstein ve Mayer, 1986, Winne, 2011; Zimmerman ve Pons, 1986) yer almaktadır. Örneğin Pintrich (1999) öz-düzenlemeli öğrenme stratejilerini bilişsel, üstbilişsel, motivasyonel stratejiler ve kaynak yönetimi stratejileri olmak üzere dört temel sınıfta ele almıştır. Zimmerman ve Pons (1986) öz değerlendirme, organize etme ve dönüştürme, hedef belirleme ve planlama, bilgiyi araştırma gibi ögeler içeren 14 adet strateji sıralamaktadır. Winne ve Hadwin Modeli (Winne, 2011) ise öz-düzenlemeli öğrenme stratejilerini görev tanımı, hedef belirleme ve planlama, çalışma taktikleri ile stratejileri uygulama ve üstbilişsel olarak çalışmaya uyarlama şeklinde dört aşamada açıklamaktadır. Araştırmacılar arasında sınıflandırmaya ilişkin bir fikir birliği olmasa da söz konusu stratejiler, genel hatlarıyla belirli kategoriler altında toplanabilmektedir. Örneğin Panadero'ya (2017) göre Zimmermann, Pintrich ve Boekaerts sınıflandırmaları motivasyon ve duygu odaklı stratejiler olarak; Zimmermann, Pintrich, Winne ve Hadwin sınıflandırmaları ise üstbilişsel stratejiler olarak ele alınabilmektedir

Waeytens, Lens ve Vandenberghe'e (2002) göre öğrenciler, okul kariyerleri aracllı̆ıyla özdüzenlemeli öğrenmelerini geliştirmeli ve öğretmenler de öğrencilerin öz-düzenlemeli öğrenme beceri ve davranışlarını geliştirmelerine yardımcı olmak için, öz-düzenlemeli öğrenmeye yönelik içerik bilgilerini, pedagojik içerik bilgilerini ve genel pedagojik bilgilerini geliştirmelidirler (Michalsky, 2014). Bunun yanı sıra öğretmenlerin öğrenme-öğretme ortamını, öğrencilerin öz-düzenleme becerilerini geliştirmelerine yönelik düzenlemeleri gerekir. Bu noktada öğretmenlerin sınıf içinde ilgili uygulamalara yönelik öz-yeterlik inançlarının yüksek olması beklenir. Çünkü "öz-yeterlik inancı bireylerin, yaşamlarını etkileyen olayları etkileme yeteneklerine olan inançlarıdır" (Bandura, 2010). Öğretmen öz-yeterliği ise "bir öğretmenin eğitimde çıkabilecek sorunlar karşısında, çözüm yolları üretebilmeye ve yapabileceği faaliyetleri ne kadar iyi yapabildiğine yönelik inancı" (Kaçar ve Beycioğlu, 2017) ve kısaca "öğretmenin öğrenci performansını etkileme yeteneğine yönelik inancı" (Ashton, 1984) şeklinde tanımlanmıştır. Yapılan araştırmalar öz-yeterlik inancı yüksek olan öğretmenlerin öğretim sürecinde yer alan temel konuları başarıyla yürüttüklerini (Kiremit, 2006), öğretimle ilgili yeni fikirlere açık olduklarını (Lee, Cawthon ve Dawson, 2012), öğrencileri için daha iyi yaşantılar oluşturduklarını (Oğuz, 2009), daha etkili öğrenme ortamları oluşturup daha az stres yaşadıklarını (Chan, 2003), öğrenci başarısını ve motivasyonunu etkileyebileceklerine inandıklarını (TschannenMoran, Woolfolk-Hoy ve Hoy, 1998) ve hatta bu inancın öğrenci başarı çıktılarını olumlu etkilediğini (Caprara, Barbaranelli, Steca ve Malone, 2006; Roberts, Henson, Tharp ve Morena, 2001; Tschannen-Moran ve Johnson, 2011) ortaya koymaktadır.

Öğretmen öz-yeterliği üzerine yürütülen araştırmalar "öğretmen öz-yeterlik inancı" şeklinde geniş bağlamda ele alınabildiği gibi öz-yeterliğin spesifik bir alan üzerine çalışılması da mümkündür. Bu noktada öğrencilerin en başta hayat boyu öğrenenler olmasında ve diğer açıklamalarla birlikte önemi açıkça ortada olan öz-düzenlemeli öğrenme stratejilerini uygulamaları noktasında kritik öneme sahip öğretmenlerin ilgili uygulamalara yönelik özyeterliklerinin yüksek olması gerekmektedir. Buna göre öğretmenlerin öz-düzenlemeli öğrenme stratejilerini uygulamaya yönelik öz-yeterliklerinin araştırılması önem kazanmaktadır. illgili literatür incelendiğinde uluslararası alan yazında De Smul vd. (2018) tarafından geliştirilen ölçeğe rastlanmıştır. Ulusal alan yazın incelendiğinde Ozan, Çelik ve Kıncal'ın (2015) öğretmenlerin özdüzenlemeli öğrenmeye ilişkin yargılarını ortaya koymayı sağlayan Öz-Düzenlemeli Öğrenme Öğretmen İnanç Ölçeği'ni Türk Kültürüne uyarladıkları; Haşlaman ve Aşkar'ın (2015) öğrencilerin öz-düzenleyici öğrenmelerinin ve öğretmenlerin öz-düzenleyici öğrenmeyi destekleyen davranışlarının araştırılmasında kullanılabilecek ölçme aracı geliştirdikleri görülmüştür. Ancak öğretmenlerin öz düzenlemeli öğrenme uygulamalarına yönelik öz-yeterlik inancının belirlenebileceği geçerli ve güvenilir bir ölçme aracına ulusal alan yazında rastlanmamıştır. Bu 
bağlamda bu araştırmanın amacl; öğretmenlerin öz düzenlemeli öğrenme stratejilerini uygulamalarına yönelik öz-yeterliklerini ortaya koymayı sağlayan De Smul vd. (2018) tarafından geliştirilen ölçme aracını Türk kültürüne kazandırmaktır. Söz konusu ölçek güncel olması, araştırmacıların da belirttiği üzere doğrudan öz-düzenlemeli öğrenmeye yönelik olması ve teori tabanlı olarak ele alınması münasebeti ile ilk olma özelliği taşımaktadır. Bu araştırma, Türkiye alan yazınında ilgili türden bir ölçme aracının olmaması sebebiyle önemli görülmektedir.

\section{YÖNTEM}

Bu araştırmada Öz-düzenlemeli Öğrenme Uygulamaları Öğretmen Öz-yeterlik Ölçeği'ni Türk Kültürüne uyarlamak ve ölçeğin psikometrik niteliklerini ortaya koymak amaçlanmıştır. Aşağıda ilk olarak Öz-düzenlemeli Öğrenme Uygulamaları Öğretmen Öz-yeterlik Ölçeği'nin orijinal formu hakkında bilgi sunulmuş, sonrasında eldeki araştırmada gerçekleştirilen uyarlama süreci hakkında detaylı bilgi verilmiştir.

\section{Öz-düzenlemeli Öğrenme Uygulamaları Öğretmen Öz-yeterlik Ölçeği Orijinal Form}

Öz-düzenlemeli Öğrenme Uygulamaları Öğretmen Öz-yeterlik Ölçeği'nin orijinal formu İngilizce'dir ve ölçek De Smul vd. (2018) tarafından öğretmenlerin sınıflarında öz-düzenlemeli öğrenme uygulamaları üzerine kendi yeterliklerini ortaya koymak amacıyla geliştirilmiştir. Araştırmacılar alan yazın taramaları sonucunda öz-düzenlemeli öğrenme öğretiminin "doğrudan öğretim" ve "dolaylı öğretim" olmak üzere iki boyuttan oluştuğunu belirlemişler ve bu boyutlara yönelik toplamda 24 madde yazmışlardır. Araştırmacılar madde yazımında maddelerin özellikle öğretmenlerin gözlenebilen eylemlerine dönük olmasına, -ebilmek, -abilmek şeklinde yeterlik ifade etmesine ve cevap seçeneklerinde eyleme yönelik yeterliğin derecelendirilmesine dikkat ettiklerini ifade etmişlerdir. Buna göre ölçekte yer alan tüm maddeler "How well can you" ifadesi ile başlamakta ve öğretmenlerin ilgili maddelere yönelik yeterliklerini derecelendirmesini içermektedir. Ölçek "Hiç yapamam (cannot do at all)" "Sınırlı düzeyde yapabilirim (can do limitedly)" "Orta düzeyde yapabilirim(can do moderately)" "Büyük ölçüde yapabilirim (can do certainly" ve "Mükemmel yapabilirim (highly certain can do)" şeklinde beşli Likert tipi yanıtlama skalasına sahip olup ölçeğin orijinalinde yer alan 5.madde örneğin şu şekildedir: "How well can you inform your students about the importance and usefulness of self-regulated learning strategies?"

Ölçeğin 24 madde ve "doğrudan öğretim" ve "dolaylı öğretim" boyutlarında yer alacağı düşünülen deneme formu, geçerlik ve güvenirlik çalışmalarının yapılması amacıyla toplam 331 sınıf öğretmenine uygulanmıştır. Yapı geçerliğini incelemek üzere 166 öğretmenden oluşan ilk grubun verisi açımlayıc faktör analizi (AFA), 165 öğretmenden oluşan diğer grubun verisi doğrulayıcı faktör analizi (DFA) çalışmaları için ikiye ayrıımıştır. AFA sonucuna göre üç madde $(8$, 20,24) ölçme aracından çıkarılmış ve dört faktör, 21 maddeden oluşan nihai form elde edilmiştir. Araştırmacıların ilgili literatür incelemeleri neticesinde ilk olarak "doğrudan öğretim" ve "dolaylı öğretim" boyutlarını oluşturdukları ve ölçek maddelerini bu boyutlara göre yazdıkları ifade edilmiştir. Illgili analizler neticesinde "dolaylı öğretim" boyutu için yazılan maddelerin 3 alt grupta toplandığı tespit edilmiştir. Daha açık bir ifade ile ölçek "doğrudan öğretim", "seçenekler sunma" "geliştirici ve karmaşık etkinlikler sunma" ile "değerlendirme sürecinin inşası" olmak üzere 4 faktörden oluşmaktadır. Sonrasında ölçeğin 21 maddelik dört faktörlü yapısının DFA ile de doğrulandığı tespit edilmiştir. Orijinal ölçek maddeleri literatüre dayalı olarak geliştirildiğinden eldeki araştırmada araştırmacılar ölçeğin İngilizce versiyonundan elenen maddelerin Türk Kültüründe çalışabileceğini düşünmüş ve 24 maddeden oluşan deneme formunun uygulanmasına karar verilmiştir. 


\section{Öz-düzenlemeli Öğrenme Uygulamaları Öğretmen Öz-yeterlik Ölçeği'nin Uyarlanması}

Öz-düzenlemeli Öğrenme Uygulamaları Öğretmen Öz-yeterlik Ölçeği'ni uyarlamak üzere yürütülen işlemler aşağıda detaylı şekilde açıklanmıştır.

Illk olarak alan yazın taraması yapılmış ve Öğretmenlerin Öz-düzenlemeli Öğrenme Uygulamaları bakımından Öz-yeterliklerini belirlemeye yönelik ölçme araçları incelenmiştir. Doğrudan ilgili amaca hizmet eden De Smul vd. (2018) tarafından geliştirilmiş olan ölçeğe ulaşılmıştır. Ölçeğin yeni olması, ölçeği geliştiren araştırmacıların da belirttiği üzere doğrudan öz-düzenlemeli öğrenmeye yönelik olması ve teori tabanlı olarak ele alınması, araçtaki maddelerin Türk Kültürüne uygun olması ilgili ölçeğin uyarlanmak üzere seçilmesinde belirleyici faktör olmuştur. Sonrasında ilgili ölçeği geliştiren araştırmacılardan ölçeği uyarlamak üzere eposta aracııı̆ı ile gerekli izinler alınmıştır. Ölçeğin orijinal formu beş kişilik çevirmen grubuna gönderilmiş ve çevirmenlerden ölçek maddelerini Türkçeye çevirmeleri istenmiştir.

Illk çevirilerin ardından araştırmacılar öncelikle "How well can you present challenging exercises that can be solved in different ways?" şeklinde soru cümlesi halinde olan orijinal ölçek maddelerinin fiiller ve yeterlik ifadelerinin Türkçe'de tam karşılanması bakımından eğitim fakültesinde farklı branşlarda (Türkçe Öğretmenliği, İngilizce Öğretmenliği, Eğitim Programları ve Öğretim, Ölçme ve Değerlendirme, Eğitim Yönetimi ve Denetimi) doktorasını tamamlamış 7 kişiden oluşan uzman grubun da görüşü doğrultusunda maddelerin önermeler şeklinde yazıımasının daha doğru olacağına karar vermişlerdir. Buna göre örneği verilen cümle Türkçe'ye "Farklı yollarla çözülebilecek zorlayıcı alıştırmalar sunabilirim." şeklinde çevrilmiştir. Yine "How well (ne kadar iyi?)" ifadesinin de yanıtlarda karşılanması amacıyla Ölçme ve Değerlendirme alanında doktora derecesine sahip 3 ayrı uzmandan görüş alınmıştır. Buna göre derecelendirmenin 5 dereceden ve iki ucunda hiç yapamam-çok iyi yapabilirim yanıtlarından oluşan doğrusal ölçek halinde oluşturulmasına karar verilmiştir. Ardından ölçek maddelerinin Türkçe versiyonu bir İngilizce dil uzmanınca yeniden İngilizceye çevrilmiştir. Ölçeğin orijinali ve Türkçe'den İngilizce'ye çevirilen maddelerin tutarlılı̆ına ilişkin iki dilbilimciden uygunluk görüşü alınmıştır. Çevirilerin tamamlanmasının ardından araştırmacılar çevirilerin uygunluğunu son olarak kontrol etmiş ve 24 maddeden oluşan taslak form oluşturulmuştur. Illgili formun başına katıımcı öğretmenler için öz düzenlemeli öğrenme stratejilerine ilişkin kısa bir bilgilendirme metni eklenmiştir.

Ölçek uyarlama çalışmalarında ilk olarak AFA sonrasında DFA işlemlerinin yürütülmesi uygun görülmektedir (Jöreskog ve Sörbom, 1993). Bu yüzden bu araştırmada da ilk olarak AFA sonrasında DFA yapılmıştır.

\section{Araştırma Grupları}

De Smul vd. (2018) araştırmalarında, geliştirdikleri ölçeğin her düzeyden (ilkokul-ortaokullise) öğretim kademesinde görevli öğretmenlere uygulanabileceğini ifade etmişler ve verilerini sınıf öğretmenlerinden toplamışlardır. Bu araştırmada da benzer bir yaklaşım izlenmiş ve araştırma farklı ilkokullarda görev yapmakta olan 561 sınıf öğretmeninin katılımı ile gerçekleştirilmiştir. Araştırma gruplarını belirlerken ilk olarak ulaşılabilirlik ilkesi dikkate alınmış, araştırma Gaziantep ili merkez ilçelerinde yürütülmüştür. AFA ve DFA uygulamalarının farklı gruplarla yürütülmesi gerekmektedir (Fabrigar, Wegener, MacCallum ve Strahan, 1999). Bu nedenle bu araştırmada da öncelikle 300 öğretmenden elde edilen veriler üzerinde AFA, ardından 261 öğretmenden toplanan veriler üzerinde DFA uygulaması gerçekleştirilmiştir. AFA grubu mesleki tecrübesi 1 yıldan 44 yıla kadar değişen 181 kadın 119 erkekten oluşmaktadır. DFA grubu mesleki tecrübesi 1 yıldan 41 yıla kadar değişen 163 kadın 98 erkekten oluşmaktadır. Yapılan t-test ve ki-kare analizlerine göre grupların mesleki tecrübe $(p=.415)$ ve cinsiyet $(p=.607)$ açısından farklılaşmadığı bir diğer deyişle benzer olduğu belirlenmiştir. Ölçeğin güvenirlik ve ölçüt geçerliği çalışmaları yine DFA grubundaki öğretmenlerden elde edilen veriler üzerinden gerçekleştirilmiştir. 
Cattell (1978) AFA için beşli Likert tipi bir ölçme aracındaki toplam madde sayısının beş katı büyüklüğün yeterli olacağını ifade etmektedir. Kline (2011) da DFA için tahmin edilen parametre sayısının 10 katının yeterli olacağını ifade etmektedir. Buna göre eldeki araştırmada AFA için 300 ve DFA için 261 örneklem büyüklükleri yeterlidir.

\section{Verilerin Analizi:}

Öz-düzenlemeli Öğrenme Uygulamaları Öğretmen Öz-yeterlik Ölçeği'nin yapı geçerliğini ortaya koymak üzere ilk olarak AFA sonrasında elde edilen yapının Türk Kültüründe doğrulanma durumunu ortaya koymak üzere de DFA uygulanmıştır. Ölçüt geçerliği için ölçeğin bütünü ve alt boyutları arasındaki korelasyona bakılmıştır. Ölçeğin güvenilirliğini belirlemek üzere ise ölçeğin tamamının ve alt boyutlarının Cronbach-alfa iç tutarlılık katsayıları, madde-toplam korelasyonları ve madde ayırt edicilikleri incelenmiştir. Il gili analizler IBM SPSS 20.0 ile IBM SPSS AMOS programları aracılığıyla yürütülmüştür.

\section{BULGULAR}

Araştırmada AFA uygulamasından önce, örneklem büyüklüğünün yeterliğini ve örneklemin faktörleşmeye uygunluğunu incelemek üzere Kaiser-Meyer-Olkin (KMO) ve Barlett Küresellik Testi değerleri incelenmiştir. Eldeki veri setinin faktörleşmeye uygunluğunun göstergelerinden biri olan KMO değeri .94 olarak hesaplanmıştır. Kalaycı'ya (2005) göre KMO değerinin .50'den fazla olması, faktör analizine devam edilebileceğini söyler ve .94 "çok iyi" olarak değerlendirilebilir. Barlett Küresellik Testi sonucu da anlamlıdır $\left[\chi^{2}=3954.510, s d=231, p<.01\right]$. Buna göre eldeki veri setinin AFA için uygun olduğu söylenebilir (Kalaycl, 2005). Öz-düzenlemeli Öğrenme Uygulamaları Öğretmen Öz-yeterlik Ölçeği'nin AFA sonuçları Tablo 1'de yer almaktadır.

\section{Tablo 1:}

Öz-düzenlemeli öğrenme uygulamaları öğretmen öz-yeterlik ölçeğinin açımlayıcı faktör analizi sonucu

\begin{tabular}{|c|c|c|c|c|c|}
\hline $\begin{array}{c}\text { Faktör 1: } \\
\text { Doğrudan } \\
\text { öğretim }\end{array}$ & $\begin{array}{l}\text { Döndürülmüş } \\
\text { Faktör } \\
\text { Yük Değeri }\end{array}$ & $\begin{array}{c}\text { Faktör 2: } \\
\text { Seçenek } \\
\text { sunma }\end{array}$ & $\begin{array}{l}\text { Döndürülmüş } \\
\text { Faktör } \\
\text { Yük Değeri }\end{array}$ & $\begin{array}{c}\text { Faktör 3: } \\
\text { Etkinlik sunumu } \\
\text { ve } \\
\text { değerlendirme } \\
\text { süreci } \\
\end{array}$ & $\begin{array}{l}\text { Döndürülmüş } \\
\text { Faktör } \\
\text { Yük Değeri }\end{array}$ \\
\hline $\mathrm{m} 1$ & .55 & m9 & .61 & $\mathrm{~m} 14$ & .50 \\
\hline $\mathrm{m} 2$ & .55 & $\mathrm{~m} 11$ & .80 & m15 & .51 \\
\hline m4 & .85 & $\mathrm{~m} 12$ & .91 & $\mathrm{~m} 16$ & .54 \\
\hline m5 & .83 & $\mathrm{~m} 13$ & .89 & $\mathrm{~m} 17$ & .72 \\
\hline $\mathrm{m} 6$ & .90 & & & $\mathrm{~m} 18$ & .67 \\
\hline $\mathrm{m} 7$ & .84 & & & m19 & .71 \\
\hline \multirow[t]{5}{*}{ m8 } & .58 & & & $\mathrm{~m} 20$ & .83 \\
\hline & & & & $\mathrm{m} 21$ & .85 \\
\hline & & & & $\mathrm{m} 22$ & .76 \\
\hline & & & & $\mathrm{m} 23$ & .65 \\
\hline & & & & $\mathrm{m} 24$ & .67 \\
\hline \multicolumn{2}{|c|}{$\begin{array}{c}\text { Özdeğer: } 1.39 \\
\text { Açıklanan Varyans: \%6.31 }\end{array}$} & \multicolumn{2}{|c|}{$\begin{array}{c}\text { Özdeğer: } 1.91 \\
\text { Açıklanan Varyans: \%8.69 }\end{array}$} & \multicolumn{2}{|c|}{$\begin{array}{c}\text { Özdeğer: } 10.03 \\
\text { Açıklanan Varyans: } \% 45.57\end{array}$} \\
\hline \multicolumn{6}{|c|}{ Açılanan Toplam Varyans: \%60.57 } \\
\hline
\end{tabular}

Temel bileşenler analizi ile yürütülen AFA çalışmasında ilk olarak maddelerin faktör yükleri incelenmiştir. Her bir madde özelinde faktör yüklerinin en az .40 olması ve yalnızca tek faktörde yüksek faktör yüküne sahip olması temel alınmıştır. Kline'a (2011) göre herhangi bir faktördeki bir maddenin faktör yükünün başka bir faktördeki yükü ile arasında en az .1 fark olmalıdır. Bu kritere göre ilk olarak 10 numaralı madde elenmiştir. 10.madde elendikten sonra AFA işlemi 
tekrarlanmış ve yeni analiz neticesinde 3.maddenin de elenmesine karar verilmiştir. Ardından tekrarlanan analizler üzerine ölçeğin 3 faktörden oluştuğu, ilgili 3 faktörün ölçeğe ilişkin varyansın toplamda \% 60.57'sini açıkladığı belirlenmiştir. Ölçeğin alt boyutları birbiri ile yüksek ilişki gösterdiğinden (bkz: Tablo 3) direct oblimin döndürme yöntemi seçilmiştir. Faktör döndürme işleminin ardından 1. faktörün 7 madde (1.2.4.5.6.7.8 numaralı maddeler), 2. faktörün 4 madde (9.11.12.13 numaralı maddeler), 3. faktörün 11 maddeden (14.15.16.17.18.19.20.21.22.23.24 numaralı maddeler) oluştuğu görülmüştür.

Öz-düzenlemeli öğrenme uygulamaları öğretmen öz-yeterlik ölçeği'nin "doğrudan öğretim" olarak isimlendirilen ilk boyutunda yedi madde yer almakta ve maddelerin direct oblimin döndürme yöntemiyle döndürülmüş faktör yükleri .55 ve .90 arasında değişmektedir. Bu faktörün tek başına açıkladığı varyans \%6.31'dır. Ölçeğin "Seçenekler sunma" olarak isimlendirilen ikinci faktöründe dört madde bulunmakta ve maddelerin döndürülmüş faktör yükleri .61 ve .91 arasında değişmektedir. Seçenekler sunma faktörü tarafından açıklanan varyans \%8.69'dur. Ölçeğin "Etkinlik sunma ve değerlendirme süreci" olarak isimlendirilen üçüncü faktöründe de on bir madde bulunmakta ve maddelerin döndürülmüş faktör yükleri .50 ve .85 arasında değişmektedir. Etkinlik sunma ve değerlendirme süreci faktörü tarafından açıklanan varyans \%45.57'dir.

Eldeki sonuçlar Öz-düzenlemeli Öğrenme Uygulamaları Öğretmen Öz-Yeterlik Ölçeği'nin orijinal formuyla kıyaslandığında öncelikle orijinal formda yer alan 3 ve 10. maddelerin Türk kültüründe elendiği, orijinal ölçekte elenen 8, 20, 24.maddelerin Türk kültüründe çalıştığı görülmüştür. Faktörler bakımından orijinal formda yer alan "geliştirici ve karmaşık etkinlikler sunma" ile "değerlendirme sürecinin inşası" boyutlarının Türk kültüründe tek boyutta toplandığı, bunun dışında ölçeğin 24 maddeden oluşan deneme formuyla birebir örtüştüğünü görülmektedir. Öz-düzenlemeli öğrenme uygulamaları öğretmen öz-yeterlik ölçeği'nin AFA sonucunda ortaya konan 22 maddelik üç faktörlü yapısı, DFA ile de incelenmiştir. DFA için Maksimum olabilirlik (ML) kestirim yöntemi tercih edilmiş, bunun için geçerli varsayımların sağlandığı tespit edilmiştir. Ölçekte yer alan 22 maddeye ait ortalama, standart sapma, çarpıklık ve basıklık değerleri Tablo 2'de; korelasyon tablosu ise Ek 2'de sunulmuştur.

Tablo 2:

Maddelere ait ortalama, standart sapma, çarpıklık, basıklık değerleri

\begin{tabular}{|c|c|c|c|c|c|c|c|c|c|}
\hline Madde No & $\begin{array}{l}\text { Aritmetik } \\
\text { Ortalama }\end{array}$ & $\begin{array}{c}\text { Standart } \\
\text { Sapma }\end{array}$ & Çarpıklık & Basıklık & Madde No & $\begin{array}{l}\text { Aritmetik } \\
\text { Ortalama }\end{array}$ & $\begin{array}{c}\text { Standart } \\
\text { Sapma }\end{array}$ & Çarpıklık & Basıklık \\
\hline m1 & 4.000 & .789 & -.378 & -.419 & m14 & 4.245 & .765 & -.760 & .066 \\
\hline m2 & 4.157 & .719 & -.369 & -.578 & m15 & 4.418 & .667 & -.795 & -.130 \\
\hline m4 & 4.088 & .806 & -.517 & -.391 & m16 & 4.130 & .817 & -.713 & .220 \\
\hline m5 & 4.180 & .771 & -.524 & -.525 & m17 & 4.134 & .785 & -.577 & -.236 \\
\hline m6 & 4.046 & .788 & -.414 & -.447 & m18 & 4.207 & .736 & -.406 & -.863 \\
\hline m7 & 4.123 & .734 & -.314 & -.716 & m19 & 4.261 & .735 & -.570 & -.542 \\
\hline m8 & 4.188 & .754 & -.705 & .521 & m20 & 4.103 & .837 & -.594 & -.194 \\
\hline m9 & 4.241 & .733 & -.707 & .487 & m21 & 4.310 & .728 & -.855 & .754 \\
\hline m11 & 4.226 & .774 & -1.017 & 1.605 & m22 & 4.307 & .732 & -.787 & .424 \\
\hline m12 & 4.230 & .745 & -.850 & .994 & m23 & 4.322 & .731 & -.941 & 1.029 \\
\hline m13 & 4.195 & .792 & -.831 & .594 & m24 & 4.150 & .849 & -.747 & .132 \\
\hline
\end{tabular}

DFA sonucu elde edilen uyum indisleri CFI .951, TLI .944, RMSEA .063, SRMR .042 şeklinde belirlenmiştir. Buna göre ölçeğin üç faktörlü yapısının DFA'ya tabi tutulmasının ardından elde edilen uyum indislerinin ki-kare değeri hariç $\left[X^{2}=409.196 \quad(p=.000)\right]$ "kabul edilebilir" ve 
"mükemmel uyum" sınırları içerisinde bulunduğu (Çokluk, Şekercioğlu ve Büyüköztürk, 2010) görülmektedir. Buna göre ilgili yapının geçerli bir model olduğu ifade edilebilir. Şekil 1'de de ölçeğin 3 faktörlü modeline ait standardize edilmiş faktör yükleri sunulmuştur.

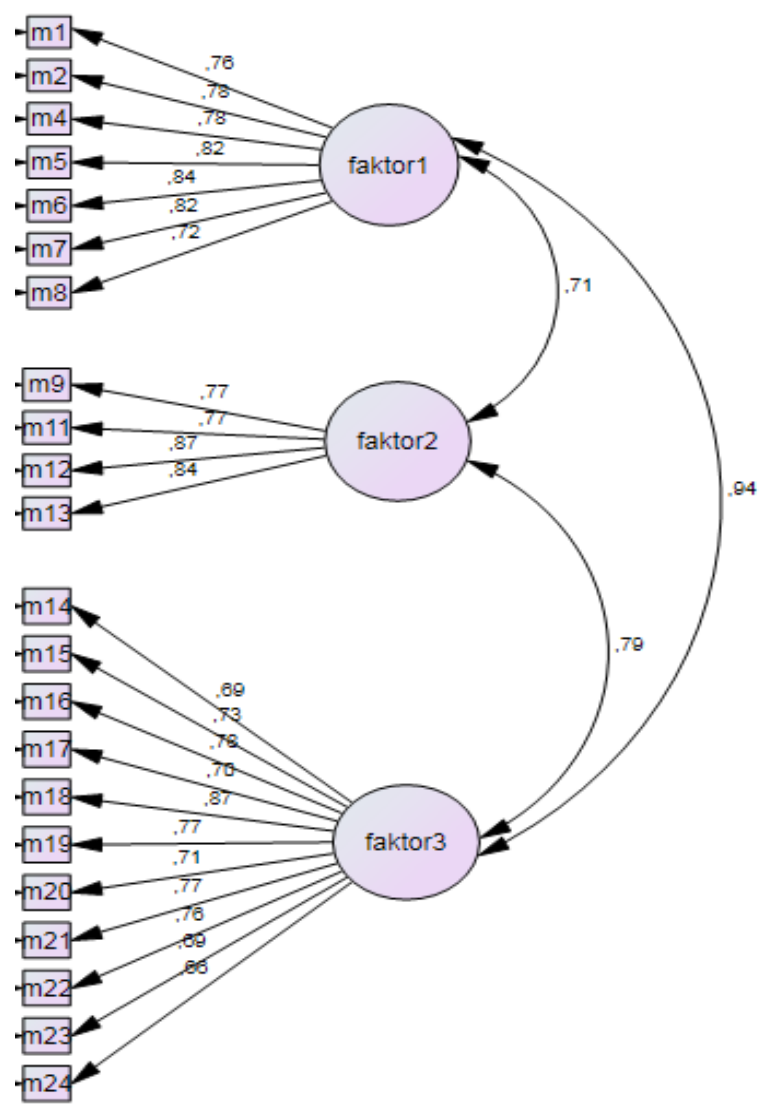

Şekil 1. Öz-Düzenlemeli Öğrenme Uygulamaları Öğretmen Öz-Yeterlik Ölçeği

Şekil 1'de görüldüğü gibi maddelerin faktör yükleri .66 ile .87 arasında yer almaktadır. Bu değerler ölçekteki bütün maddelerin örtük değişkeni açıklamada yeterli t değerlerinin olduğunu göstermektedir.

\section{Ölçüt geçerliği}

Ölçeğin ölçüt geçerliğine kanıtlar üretmek amacıyla ölçek toplam puanı ve faktörler arası korelasyon katsayısı $(r)$ hesaplanmıştır. Bulgular Tablo 3'te sunulmuştur.

Tablo 3:

Ölçek toplam puanı ve faktörleri arasındaki korelasyonlar

\begin{tabular}{lllll} 
& & Faktör 1 & Faktör 2 & Faktör $\mathbf{3}$ \\
\hline Toplam & $\boldsymbol{r}$ & $.929^{\star *}$ & $.819^{\star *}$ & $.969^{\star *}$ \\
\hline Faktör 1 & $\boldsymbol{r}$ & & $.658^{\star *}$ & $.850^{\star *}$ \\
\hline Faktör 2 & $\boldsymbol{r}$ & & & $.732^{\star *}$ \\
\hline
\end{tabular}

** Korelasyon .01 düzeyinde anlamlıdır.

Tablo 3'e göre ölçeğin toplam puanı ile faktörleri arasında yüksek, pozitif ve anlamlı ilişki vardır. Diğer deyişle ölçeğin geneli ölçüt olarak kabul edildiğinde, ölçek alt faktörleri ile uyumludur. 


\section{Güvenirlik}

Güvenirlik çalışmaları kapsamında Cronbach's Alpha, Omega veya CR değeri (Şen, 2020) hesaplanabilir. Bu araştırmada güvenirlik katsayısı için DFA verileri üzerinden 2 maddenin elenmesi ile 22 maddelik nihai hali oluşturulan ölçeğin geneli ve alt boyutlarına ilişkin Cronbach's Alpha değeri hesaplanmıştır. Hesaplanan Cronbach's Alpha güvenirlik katsayısı ölçeğin geneli için .962; doğrudan öğretim boyutu için .921; seçenekler sunma boyutu için .884; etkinlik sunma ve değerlendirme boyutu için .932 olarak hesaplanmıştır. .70 ve üzerindeki güvenirlik katsayısı referans (Bernardi, 1994) kabul edildiğinde elde edilen değerlerin ölçeğin güvenirliğine kanıt oluşturduğu söylenebilecektir.

Ölçeğin iç tutarılıığına ek kanıtlar üretmek amacıyla madde-toplam korelasyonu ve \%27'lik alt grup( $(n=71)$-üst grup $(n=71)$ madde ayırt edicilik değerleri de hesaplanmıştır. Tablo 4 'te ölçme aracında bulunan her bir maddeye ilişkin madde-toplam korelasyonu ile \%27'lik alt grup-üst grup puanları arasındaki farka ait $\mathrm{t}$ testi bulguları sunulmuştur.

\section{Tablo 4:}

Madde Toplam Korelasyonları (MTK) ile \%27'lik alt grup-üst grup puanları arasındaki farka ilişkin $t$ testi sonuçları

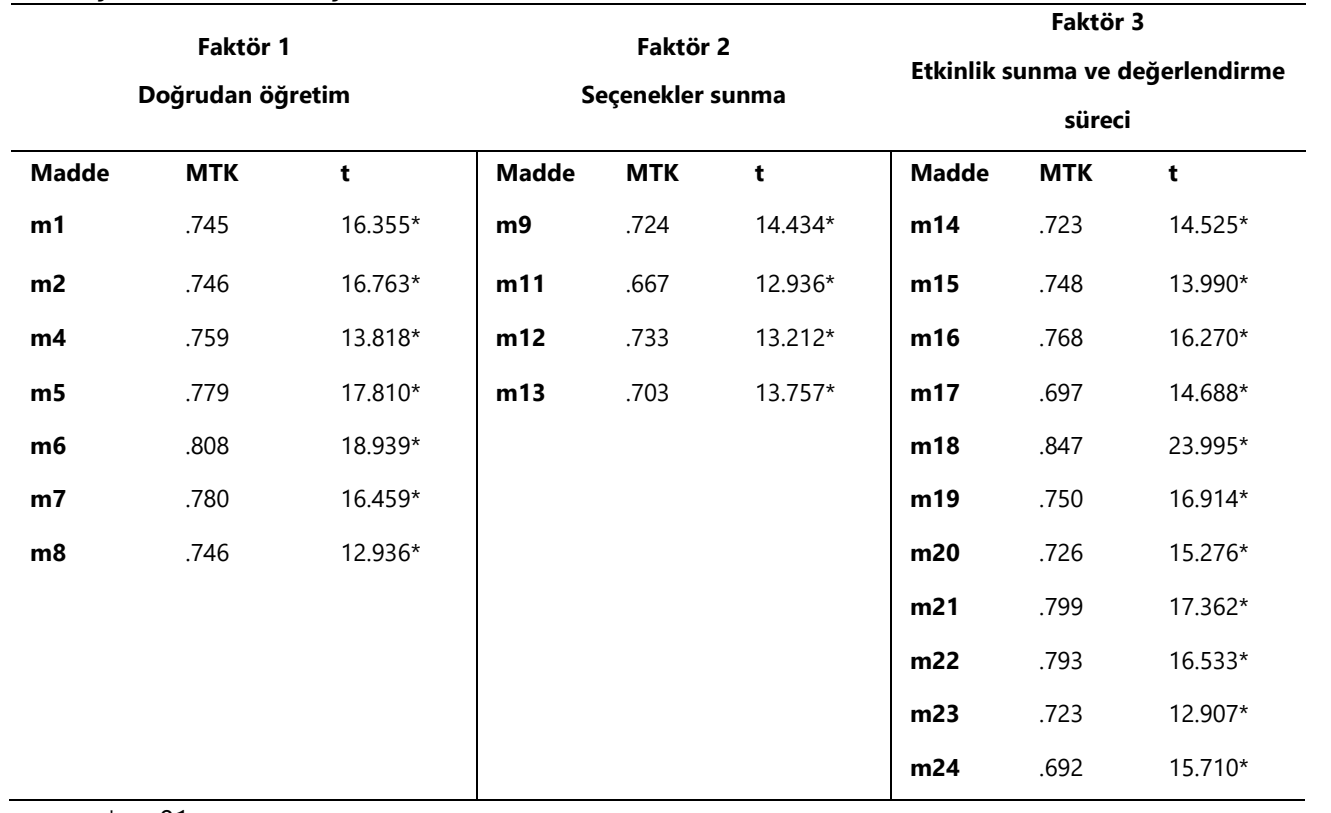

${ }^{*} p<.01$

Tablo 4'te görüldüğü üzere, madde toplam korelasyonları .667 ile .847 arasında değişmektedir. Korelasyonların tümü istatistiksel olarak 01 düzeyinde anlamlıdır. Bu bulgu ölçme aracında yer alan maddelerin her birinin ölçeğin genel toplam puanı ile pozitif, orta ve yüksek düzeyde ilişkili olduğunu söylemektedir. Daha açık ifade ile ölçekte yer alan her bir madde ölçek ile tutarlıdır. Tabloda ayrıca görüldüğü üzere t testi değerleri de; 12.907 ile 23.995 arasında değişmektedir ve $t$ değerlerinin tümü istatistiksel olarak .01 düzeyinde anlamlıdır. Bu bulgu da maddelerin tamamının ayırt edici olduğunu göstermektedir.

\section{SONUÇ ve ÖNERILER}

Eldeki araştırmada Öz-düzenlemeli Öğrenme Uygulamaları Öğretmen Öz-yeterlik Ölçeği'ni geliştiren araştırmacılar tarafından orijinal formdan AFA sonucunda çıkarılmasına karar verilen 8 , 20, 24 numaralı maddelerin Türk Kültürü'nde çalışıp çalışmadığı incelenmiştir. Bir başka deyişle araştırmacıların ölçeğin deneme uygulaması için hazırladığı 24 maddelik ilk halinin 
uygulanmasına karar verilmiştir. Türk Kültürüne uyarlama sürecinde, geçerlilik çalışması için ölçeğin yapı geçerliği için AFA ve DFA; ölçüt geçerliği için ölçeğin toplam puanı ile alt boyutlarından elde edilen puanlar arası korelasyon hesaplanmıştır. Ölçeğin güvenirlik çalışması kapsamında da ölçeğin tamamının ve faktörlerinin Cronbach-alfa iç tutarlılık katsayıları, madde toplam korelasyonları ile \%27'lik alt grup( $n=71)$-üst grup $(n=71)$ madde ayırt edicilikleri hesaplanmıştır. Yürütülen geçerlik ve güvenirlik analizlerine göre, ölçeğin ilk halindeki 3 ve 10 numaralı maddelerin dışındaki tüm maddelerin Türk Kültürü'nde çalıştığı tespit edilmiştir. Araştırmada gerçekleştirilen analizlerin tümü, uyarlanan ölçme aracından elde edilen sonuçların geçerlik ve güvenirliğine kanıt olarak sunulabilir. Ölçeğin son formu Ek 1'de sunulmuştur. Ölçek olumsuz madde içermemektedir ve ölçekten alınabilecek puan en az 22 en çok 110'dur.

İlgili alanda öğretmenlerin öz-düzenlemeli öğrenme uygulamalarına ilişkin öz-yeterliklerini ortaya koymayı sağlayacak bir ölçme aracının yer almaması eldeki çalışmayı gerekli ve önemli kılmaktadır. Ölçek, sınıf öğretmenleri ile uyarlanmıştır ancak ölçeği geliştiren araştırmacılar maddelerin ilkokullar için özel olarak hazırlanmadığını, her düzeyden (ilkokul-ortaokul-lise) öğretim kademesinde görevli öğretmenlere yeni bir uyarlama sürecine ihtiyaç duyulmaksızın uygulanabileceğini ifade etmişlerdir. Geçerlik ve güvenirliği kanıtlanan eldeki ölçek ile öğretmenlerin öz-düzenlemeli öğrenme uygulamalarına ilişkin alt boyutlardaki öz-yeterlikleri belirlenerek eksiklikler giderilebilir. Daha açık ifade ile ölçekten elde edilecek sonuçlar ile öğretmenlerin öz-düzenlemeli öğrenme uygulamalarında kendilerini yetersiz hissettikleri alanlar ortaya konularak bu alanları geliştirici çalışmalar yapılabilir. Böylece sınıf içi öğretim süreçleri öğrenenlerin 21.yy becerilerinden öğrenmeyi öğrenme becerilerini edinmelerinde daha etkili hale getirilebilir. Nitekim araştırmanın giriş bölümünde de detaylıca ifade edildiği gibi öğretmen inancı hem öğretmenin kendi davranışlarını hem de öğrenci davranışlarını belirleyen etkiye sahiptir.

Ölçeğin orijinal halinde kabul edilen 21 maddeden oluşan dört faktörlü yapı için de DFA yapılabilir. İlgili yapının Türk Kültürü'nde çalışıp çalışmadığı incelenebilir. Diğer yandan ölçeği geliştiren araştırmacıların araştırmalarında önerdiği gibi bu ölçek spesifik bir alana kolayca uyarlanabilir (örneğin matematik dersinde öz-düzenlemeli öğrenme uygulamaları öz-yeterliği) böylece farkıı alanlarda öz-düzenlemeli öğrenme uygulamaları arasındaki fark incelenebilir. Tüm bunlarla birlikte ölçekten elde edilecek puanlarda öğretmenlerin kendilerini değerlendirdiği ve elde edilen sonuçların bu sınırlılık içerisinde değerlendirilmesi gereği göz önünde bulundurulmalıdır. Bu bağlamda gelecek çalışmaların hem ölçek yanıtları hem de ölçeğe yanıt veren öğretmenlerin gözlemlendiği karma yaklaşımlar şeklinde düzenlenmesi daha gerçekçi sonuçlar ortaya koyabilir.

\section{KAYNAKÇA}

Ashton, P. T. (1984). Teacher efficacy: A motivational paradigm for effective teacher education. Journal of Teacher Education, 35(5), 28-32.

Bandura, A. (2010). Self-efficacy. The Corsini Encyclopedia of Psychology, 1-3. doi:10.1002/9780470479216.corpsy0836.

Boekaerts, M., \& Corno, L. (2005). Self-regulation in the classroom: A perspective on assessment and intervention. Applied Psychology: An Internatıonal Review, 54(2), 199-231.

Bolhuis, S. (2003). Towards process-oriented teaching for self-directed lifelong learning: A multidimensional perspective. Learning and Instruction, 13(3), 327-347. Doi: 10.1016/S0959-4752(02)00008-7.

Büyüköztürk, Ş. (2011). Sosyal bilimler için veri analizi el kitabı: istatistik, araştırma deseni, SPSS uygulamaları ve yorum. (14. baskı). Ankara: Pegem Akademi Yayınları.

Caprara, G. V., Barbaranelli, C., Steca, P., \& Malone, P. S. (2006). Teachers' self-efficacy beliefs as determinants of job satisfaction and students' academic achievement: a study at the school level. Journal of School Psychology, 44, 473-490. 
Cattell, R. B. (1978). The scientific use of factor analysis in behavioral and life sciences. New York: Plenum Press.

Chan, D. W. (2003). Multiple intelligences and perceived self-efficacy among Chinese secondary school teachers in Hong Kong. Educational Psychology, 23(5), 521-533.

Chen, Z., Ma, N., \& Liu, B. (2015). Lifelong learning for sentiment classification. In Proceedings of Association for Computational Linguistics, 750-756.

Çokluk, Ö., Şekercioğlu, G. ve Büyüköztürk, Ş. (2010). Sosyal bilimler için çok değişkenli istatistik: SPSS ve LISREL uygulamaları. (3. Baskı). Ankara: Pegem Akademi.

De Smul, M., Heirweg, S., Van Keer, H., Devos, G., \& Vandevelde, S. (2018). How competent do teachers feel instructing self-regulated learning strategies? Development and validation of the teacher selfefficacy scale to implement self-regulated learning. Teaching and Teacher Education, 71, 214-225.

Dignath, C., \& Büttner, G. (2008). Components of fostering self-regulated learning among students. A meta-analysis on intervention studies at primary and secondary school level. Metacognition and Learning, 3(3), 231-264.

Dinsmore, D. L., Alexander, P. A., \& Loughlin, S. M. (2008). Focusing the conceptual lens on metacognition, self-regulation, and self-regulated learning. Educ Psychol Rev, 20, 391-409. Doi: 10.1007/s10648008-9083-6.

Doğan, S., \& Çalışkan Toyoğlu, A. (2019). Okullarda hayat boyu öğrenme yeterlilikleri. Bir durum çalışması. Electronic Journal of Social Sciences, 18(71), 1325-1348.

Fabrigar, L. R., Wegener, D. T., MacCallum, R. C., \& Strahan, E. J. (1999). Evaluating the use of exploratory factor analysis in psychological research. Psychological Methods, 4(3), 272-299.

Formosa, M. (2019). Active ageing through lifelong learning: The university of the third age. In: Formosa M. (eds) The university of the third age and active ageing. International perspectives on aging, 23. Springer, Cham. Doi: 10.1007/978-3-030-21515-6_1.

Garcia, T., \& Pintrich, P. R. (1994). Regulating motivation and cognition in the classroom: The role of selfschemas and self-regulatory strategies. In D. H. Schunk, \& B. J. Zimmerman, Self-regulation of learning and performance: Issues and educational applications (pp. 127-153). Hillsdale, NJ: Lawrence Erlbaum Associates.

Graves, M. R. (2018). Lifelong learning: Applying cognitive load theory to elder learners suffering from agerelated cognitive decline. SFU Educational Review, 11(1), 91-97. Doi: 10.21810/sfuer.v11i1.755.

Gündoğdu, K., Yüksel, S., \& Akyol, B., \& Vural, R. A. (2016). Hayat boyu öğrenme konusunda yayımlanan tez ve makalelere ilişkin bir içerik analizi: 2000-2015. Erzincan Üniversitesi Eğitim Fakültesi Dergisi, 18(2), 1491-1513. Doi: 10.17556/jef.88957.

Haşlaman, T., \& Aşkar, P. (2007). Programlama dersi ile ilgili özdüzenleyici öğrenme stratejileri ve başarı arasındaki ilişkinin incelenmesi. Hacettepe Üniversitesi Eğitim Fakültesi Dergisi, 32, 110-122.

Haşlaman, T., \& Aşkar, P. (2015). Öğrencilerin özdüzenleyici öğrenmelerinin ve öğretmenlerin özdüzenleyici öğrenmeyi destekleyen davranışlarının ölçülmesi. Hacettepe Üniversitesi Eğitim Fakültesi Dergisi, 30(1), 106-121.

Inan, B., \& Yüksel, D. (2010). Self-regulated learning: How is it applied as a part of teacher training through diary studies?. Procedia-Social and Behavioral Sciences, 3, 116-120. Doi: 10.1016/j.sbspro.2010.07.021

Israel, E. (2007). Özdüzenleme eğitimi, fen başarısı ve özyeterlilik. Yayınlanmamış Doktora Tezi, Dokuz Eylül Üniversitesi, Eğitim Bilimleri Enstitüsü, İzmir.

Jöreskog, K., \& Sörbom, D. (1989). LISREL 7 user's reference guide. Chicago: Scientific Software.

Kaçar, T., \& Beycioğlu, K. (2017). İlköğretim öğretmenlerinin özyeterlik inançlarının çeşitli değişkenler açısından incelenmesi. Ilköğretim Online, 16(4), 1753-1767, Doi: 10.17051/ilkonline.2017.342988.

Kalaycı, Ş. (2005). SPSS Uygulamalı Çok Değişkenli İstatistik Teknikleri. Ankara: Asil Yayın Dağıtım.

Kiremit, H. (2006). Fen bilgisi öğretmenliği öğrencilerinin biyoloji ile ilgili öz yeterlik inançlarının karşılaştırılması. Yayınlanmamış Doktora Tezi, Dokuz Eylül Üniversitesi, Eğitim Bilimleri Enstitüsü, İzmir.

Kline, R. B. (2011). Principles and practice of structural equation modeling. New York: Guilford publications.

Lavasani, M. G., Mirhosseini, F. S., Hejazi, E., \& Davoodi, M. (2011). The effect of self-regulation learning strategies training on the academic motivation and self-efficacy. Social and Behavioral Sciences, 29, 627-632. Doi:10.1016/j.sbspro.2011.11.285.

Lee, B., Cawthon, S., \& Dawson, K. (2012). Elementary and secondary teacher self-efficacy for teaching and pedagogical conceptual change in drama based professional development program. Teaching and Teacher Education, 30, 84-98. 
Mahmoodi, M. H., Kalantari, B., \& Ghaslani, R. (2014). Self-Regulated learning (srl), motivation and language achievement of Iranian efl learners. Social and Behavioral Sciences, 98, 1062-1068. doi: 10.1016/j.sbspro.2014.03.517.

Michalsky, T, \& Schechter, C. (2013). Preservice teachers' capacity to teach self-regulated learning: Integrating learning from problems and learning from successes. Teaching and Teacher Education 30, 60-73. Doi: 10.1016/j.tate.2012.10.009.

Michalsky, T. (2014). Developing the SRL-PV assessment scheme: Preservice teachers' professional vision for teaching self-regulated learning. Studies in Educational Evaluation, 43, 214-229. Doi: 10.1016/j.stueduc.2014.05.003.

Olakanmi, E. E., \& Gumbo, M. T. (2017). The effects of self-regulated learning training on students' metacognition and achievement in chemistry. International Journal of Innovation in Science and Mathematics Education, 25(2), 34-48.

Ozan, C., Çelik, N., \& Kıncal, R. (2014). Öz-düzenlemeli Öğrenme Öğretmen İnanç Ölçeği'nin dilsel eşdeğerlik, geçerlik ve güvenirlik çalışması. I. Eurasian Educational Research Congress, 24-26 Nisan, İstanbul, Türkiye.

Panadero, E. (2017). A review of self-regulated learning: Six models and four directions for research. Front. Psychol, 8, 422. Doi: 10.3389/fpsyg.2017.00422.

Paris, S. G., \& Paris, A. H. (2001). Classroom applications of research on self-regulated learning. Educational Psychologist, 36(2), 89-101.

Pintrich, P. R. (1999). The role of motivation in promoting and sustaining self-regulated learning. International Journal of Educational Research, 31(6), 459-470.

Roberts, J. K., Henson, R. K., Tharp, B. Z., \& Morena, N. P. (2001). An examination of change in teacher selfefficacy beliefs in science education based on the duration of in-service activities. Journal of Science Teacher Education, 12(3), 199-213.

Samancı, O., \& Ocakçı, E. (2017). Hayat boyu öğrenme. Bayburt Eğitim Fakültesi Dergisi, 12(24), 711-722.

Şen, S. (2020). Mplus ile Yapısal Eşitlik Modellemesi Uygulamaları. (1. Basım). Ankara: Nobel Akademik Yayıncilık

Şencan, H. (2005). Sosyal ve davranışsal ölçümlerde güvenilirlik ve geçerlilik. (1. Basım). Ankara: Seçkin Yayınları.

Şentürk, Ş., \& Duran, V. (2020). Lifelong learning tendencies of trainers in adult education. International Journal of Evaluation and Research in Education, 9(1), 1-9.

Tschannen-Moran, M., \& Johnson, D. (2011). Exploring literacy teachers' selfefficacy beliefs: Potential sources at play. Teaching and Teacher Education, 27, 751-761.

Tschannen-Moran, M., Woolfolk-Hoy,A., \& Hoy, W. K. (1998). Teacher efficacy: Its meaning and measure. Review of Educational Research, 68(2), 202-248.

Weinstein, C. E., \& Mayer, R. E. (1986). The teaching of learning strategies. In M. Wittrock, Handbook of research on teaching (pp. 315-327). New York: Macmillan.

Winne, P. H. (2005). A perspective on state-of-the-art research on self-regulated learning. Instructional Science, 33(5e6), 559e565. Doi: 10.1007/s11251-005-1280-9.

Winne, P. H. (2011). A cognitive and metacognitive analysis of self-regulated learning. In Handbook of SelfRegulation of Learning and Performance, eds B. J. Zimmerman and D. H. Schunk (New York, NY: Routledge), 15-32.

Zimmerman, B. J., \& Pons, M. M. (1989). Development of a structured interview for assesing student use of self-regulated learning strategies. American Educational Research Journal, 23(4), 614-628.

Zimmerman, B. J. (1989). A social cognitive view of self-regulated academic learning. Journal of Educational Psychology, 81(3), 329-339.

Zimmerman, B. J. (1990). Self-regulated learning and academic achievement: An overview. Educational Psychologist, 25(1), 3-17.

Zimmerman, B. J. (2002). Becoming a self-regulated learner: An Overview. Theory into Practice, 41(2), 64-70. Doi: $10.1207 /$ s15430421tip4102_2.

Zimmerman, B. J., \& Bandura, A. (1994). Impact of self-regulatory influences on writing course attainment. American Educational Research Journal, 31(4), 845-862. 


\title{
Adaptation of the Teacher Self-Efficacy Scale to Implement Self-Regulated Learning into Turkish Culture
}

\section{Dr.Sevilay Çırak Kurt}

Adıyaman University-Turkey

sevilaycirak@hotmail.com

\author{
Dr.Esen Turan Özpolat \\ Adıyaman University-Turkey \\ esen.turan@hotmail.com
}

\begin{abstract}
The present study was carried out to adapt the "Teacher Self-efficacy Scale to Implement Self-regulated Learning" to Turkish culture and to analyse its psychometric properties in order to determine the self-efficacy of teachers in selfregulated learning practices for their classrooms. Research data were collected from 561 primary school teachers. Exploratory Factor Analysis was performed with a data set of 300 teachers to test the construct validity of the scale, and then Confirmatory Factor Analysis was conducted through a data set of 261 teachers independent of the former one. Based on the validity and reliability studies, a 22-item three-factor structure was confirmed namely self-efficacy for direct instruction, self-efficacy for providing choices, self-efficacy for providing tasks, and evaluating. As a result, it can be alleged that the Turkish form of the Teacher Self-efficacy Scale to Implement Selfregulated Learning is a valid and reliable instrument to be used to determine the teachers' self-efficacy in self-regulated learning practices.
\end{abstract}

Keywords: Self-regulated learning, Teacher self-efficacy, Scale adaption, Validity and reliability 


\section{EXTENDED ABSTRACT}

Purpose: This study aimed to adapt a valid and reliable instrument to Turkish culture to reveal the self-efficacy of teachers in self-regulated learning strategies. It is regarded to be important due to the lack of a similar scale in Turkish literature.

Method: It was a descriptive study as part of the quantitative research methods. The original form of the Teacher Self-efficacy Scale to Implement Self-regulated Learning was developed by De Smul et al (2018) in English. The motives in selecting the scale to be adapted were that it was a recent and original scale and it comprised favourable items for Turkish Culture. The original form of the scale was forwarded to a group of five translators to translate the scale items into Turkish. During the adaptation phase, CFA was performed after EFA. The principle of attainability was primarily taken into consideration in determining the research groups, and the study was conducted in the central districts of Gaziantep. The EFA and CFA procedures should be carried out with different participating groups (Fabrigar, Wegener, MacCallum \& Strahan, 1999). Thus, Exploratory Factor Analysis was initially performed with a data set obtained from 300 teachers, and it was followed by a confirmatory factor analysis with a different data set of 261 teachers. According to the $t$-test and chi-square analysis, it was determined that the groups did not differ in terms of professional seniority $(p=.415)$ and gender $(p=.607)$. That is to say, the groups were found to be similar. The reliability and criterion validity studies of the scale were also performed on the obtained data with teachers in the CFA group. The correlation between the whole scale and its sub-dimensions was examined for criterion validity. The Cronbach's alpha internal consistency coefficients, item-total correlation, and item discrimination indices for the entire scale, and its sub-dimensions were estimated to test the reliability of the scale.

Findings: Before employing EFA, Kaiser-Meyer-Olkin (KMO) [.94] and Barlett Sphericity Test $\left[\mathrm{X}^{2}=3954.510, d f=231, p<.01\right]$ were scrutinized for the adequacy of the sample size and the suitability of the sample for factor analysis, and EFA was performed after determining the acceptability of these scores. The EFA analysis was primarily based on the fact that each item should have at least a factor load of .40 and have a high factor load for only one factor. Based on these criteria, the 10th and the 3rd items were eliminated respectively, and after the subsequent analyses, the scale was found to be composed of 3 factors, and those 3 factors explained $60.57 \%$ of the total variance. Factor rotations revealed that the 1st factor included 7 items (items numbered $1,2,4,5,6,7,8)$, 2nd factor consisted of 4 items (items numbered 9, 9,11,12,13), and 3rd factor was composed of 11 items (items numbered 14,15,16,17,18,19,20,21,22,23,24).

The first sub-dimension of the Teacher Self-efficacy Scale to Implement Self-regulated Learning, called direct instruction, included seven items, and factor loads rotated by the direct oblimin rotation method ranged between .55 and .90 . The variance explained by this factor was $6.31 \%$. The second sub-dimension of the scale, called providing choices, included four items, and the rotated factor loads of the items ranged between .61 and .91. The variance explained by the factor of providing choices was $8.69 \%$. The third sub-dimension of the scale called providing tasks and evaluating included eleven items, and the rotated factor loads ranged between .50 and .85 . The variance explained by the factor of providing tasks and evaluating was $45.57 \%$.

The comparison of the available results with the original form of the scale yielded that the 3rd and the 10th items in the original form were eliminated in Turkish culture, but the 8th, the 20th and the 24th items removed from the original scale were reliable and valid in Turkish culture. It was observed that there was a one-to-one correspondence between the scale and the 24-item pilot scheme though the sub-dimensions of "providing challenges and complex tasks" and "building in evaluation" in the original form were gathered under one dimension in Turkish culture. The 22item three-factor structure of the Teacher Self-efficacy Scale to Implement Self-regulated Learning based on EFA was also tested through CFA, and the fit indices indicated that the structure offered a valid model. It was determined that the correlations between the factors and the total score of the 
scale were high, positive, and significant which produced evidence for the criterion validity of the scale.

For reliability, the Cronbach's Alpha reliability coefficient based on the CFA data for the final form of the 22-item overall scale and its sub-dimensions was estimated to be 962 for the overall scale, .921 for the sub-dimension of direct instruction, .884 for the sub-dimension of self-efficacy for providing choices, and .932 for the sub-dimension of self-efficacy for providing tasks and evaluating.

The item-total correlations estimated to produce additional evidence for the reliability of the scale varied between .667 and .847 and all of them were statistically significant at .01 level. Based on the 27\% lower ( $n=71)$-upper groups $(n=71)$ item discrimination indices, $t$-test values varied between 12.907 and 23.995 and all the $t$ values were significant at .01 level. All these implied that there was a positive moderate and high correlation between each item included in the instrument and the overall score of the scale, and all the items were discriminant.

Conclusion: All of the analyses confirmed that the adapted instrument is valid and reliable. The scale does not contain any negative items and the total score to be obtained from the scale presented in the appendix is 22 at least and 110 at most.

The lack of an instrument in Turkish literature to reveal teachers' self-efficacy in self-regulated learning practices makes the present study essential and significant. The scale was adapted through primary school teachers, but the researchers who developed the scale noted that the items were not prepared specifically for primary schools, and it could be administered to teachers working at all educational levels (primary-secondary-high school) without a newer adaptation procedure. The shortcomings may be overcome by determining the teachers' self-efficacy for the sub-dimensions of self-regulated learning practices through the scale found to be valid and reliable. More explicitly, the aspects for which teachers feel incompetent regarding self-regulated learning practices can be identified and developed through the results obtained from the scale. Thus, classroom teaching processes can be provided to be more effective for learners acquiring learning to learn skills among 27st-century skills. As stated in detail in the introductory part of the study, teacher belief has a decisive effect on both teacher and student behaviours. 


\section{Ek 1: Öz-Düzenlemeli Öğrenme Uygulamaları Öğretmen Öz-Yeterlik Ölçeği}

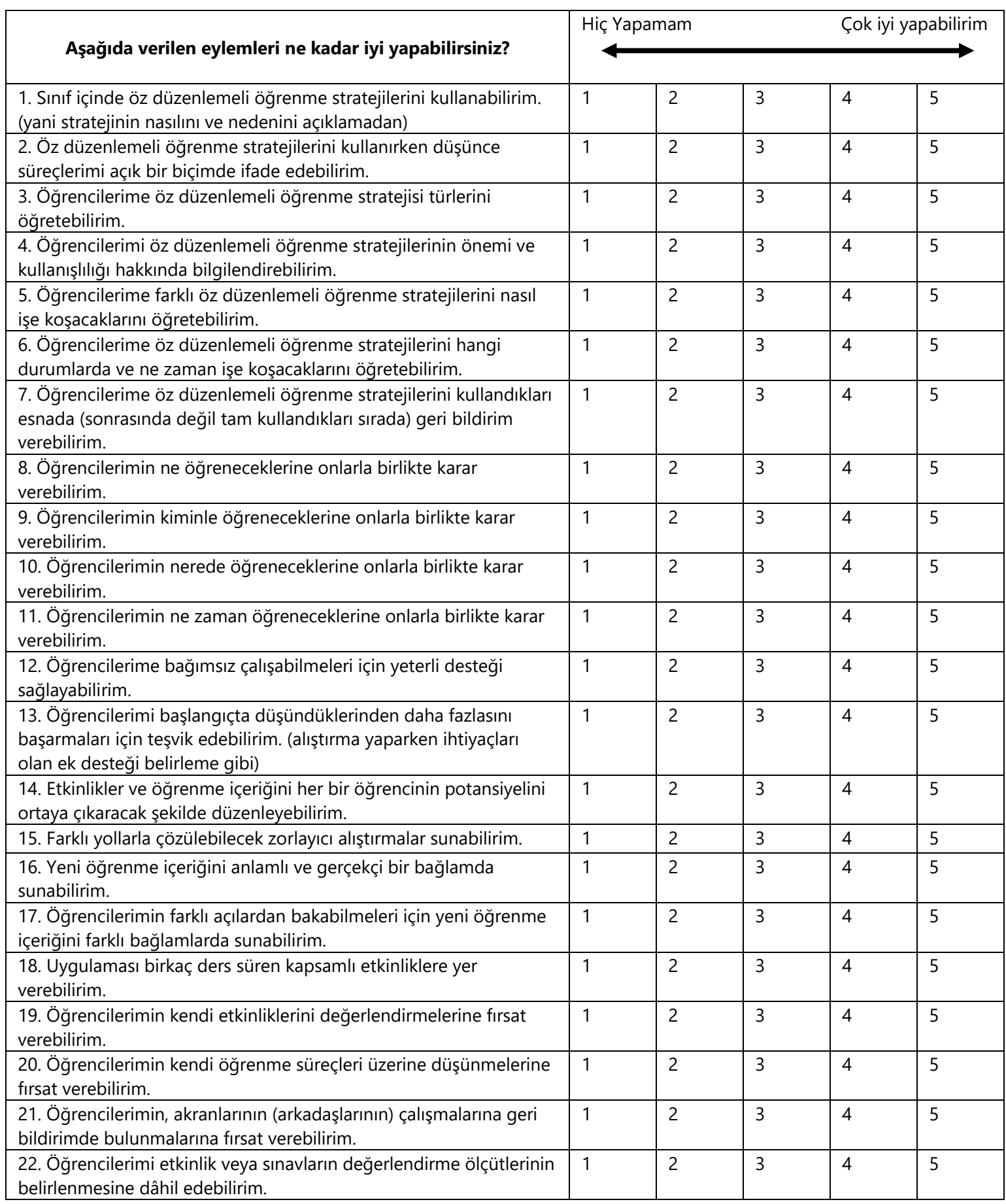





\section{Ek 2: Maddeler arası korelasyon değerleri}

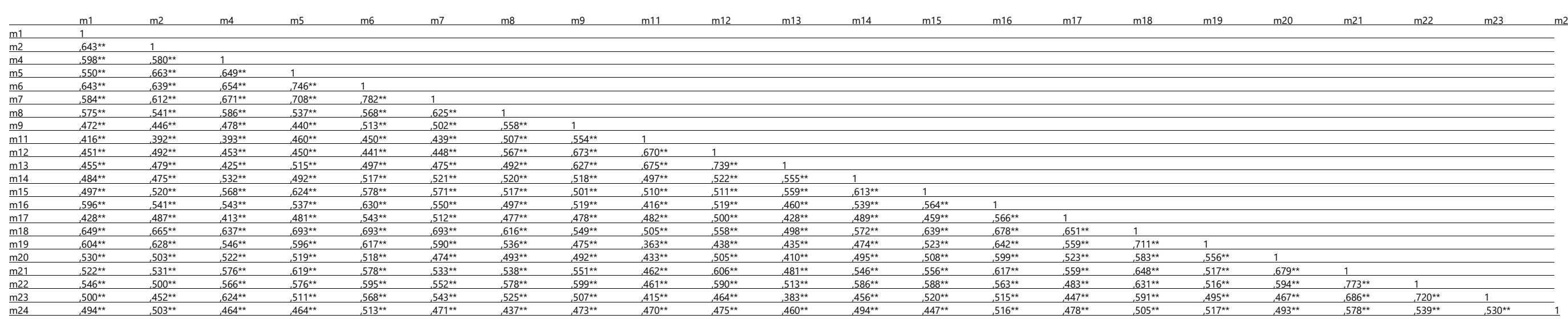

